\title{
The relation between multiple pains and mental disorders: Results from the World Mental Health Surveys
}

\author{
Oye Gureje ${ }^{\text {a,* }}$, Michael Von Korff ${ }^{b}$, Lola Kola ${ }^{c}$, Koen Demyttenaere ${ }^{\text {d }}$, Yanling He ${ }^{\text {e }}$, \\ José Posada-Villa ${ }^{\mathrm{f}}$, Jean Pierre Lepine ${ }^{\mathrm{g}}$, Matthias C. Angermeyer ${ }^{\mathrm{h}}$, \\ Daphna Levinson ${ }^{\mathrm{i}}$, Giovanni de Girolamo ${ }^{\mathrm{j}}$, Noboru Iwata ${ }^{\mathrm{k}}$, Aimee Karam ${ }^{1}$, \\ Guilherme Luiz Guimaraes Borges ${ }^{\mathrm{m}}$, Ron de Graaf ${ }^{\mathrm{n}}$, Mark Oakley Browne ${ }^{\mathrm{o}}$, \\ Dan J. Stein ${ }^{\mathrm{p}}$, Josep Maria Haro ${ }^{\mathrm{q}}$, Evelyn J. Bromet ${ }^{\mathrm{r}}$, Ron C. Kessler ${ }^{\mathrm{s}}$, Jordi Alonso ${ }^{\mathrm{t}}$ \\ ${ }^{a}$ Department of Psychiatry, University of Ibadan, Ibadan, Nigeria \\ ${ }^{\mathrm{b}}$ Center for Health Studies, Group Health Cooperative, Seattle, United States \\ ${ }^{\mathrm{c}}$ Medical Social Services Department, University College Hospital, Ibadan, Nigeria \\ ${ }^{\mathrm{d}}$ University Hospital, Gasthuisburg, Belgium \\ e Shanghai Mental Health Center, Shanghai, China \\ ${ }^{\mathrm{f}}$ Colegio Mayor de Cundinamarca University, Saldarriaga Concha Foundation, Colombia \\ ${ }^{\mathrm{g}}$ Hospital Fernaud Widal, Paris 75010, France \\ ${ }^{\mathrm{h}}$ University of Leipzig, Department of Psychiatry, Leipiz, Germany \\ ${ }^{i}$ Research and Planning, Mental Health Services, Ministry of Health, Tel Aviv, Israel \\ ${ }^{\mathrm{j}}$ Department of Mental Health, AUSL di Bologna, Italy \\ ${ }^{\mathrm{k}}$ Department of Clinical Psychology, Hiroshima International University, Hiroshima, Japan \\ ${ }^{1}$ St. George Hospital University Medical Center, Department of Psychiatry and Psychology and Balamand University Medical School, Lebanon \\ ${ }^{\mathrm{m}}$ National Institute of Psychiatry, Mexico \\ ${ }^{\mathrm{n}}$ Netherlands Institute of Mental Health and Addiction, Utrecht, The Netherlands \\ ${ }^{\circ}$ Rural Psychiatry, Monash University, Melbourne, Australia \\ ${ }^{\mathrm{p}}$ Department of Psychiatry and Mental Health, University of Cape Town, Cape Town, South Africa \\ ${ }^{4}$ Sant Joan de Deu-SSM, Barcelona, Spain \\ ${ }^{\mathrm{r}}$ Psychiatry, SUNY Stony Brook, United States \\ ${ }^{\mathrm{s}}$ Health Care Policy, Harvard Medical School, Boston, United States \\ ${ }^{\mathrm{t}}$ Health Services Research Unit, Institut Municipal d'Investigacio Medica (IMIM), Spain
}

Received 14 September 2006; received in revised form 2 May 2007; accepted 2 May 2007

\begin{abstract}
It is unclear whether differences exist in the prevalence of mood, anxiety and alcohol use disorders among persons with multiple pain conditions compared with those with single pain problems. We conducted population surveys in 17 countries in Europe, the Americas, the Middle East, Africa, Asia, and the South Pacific. Participants were community-dwelling adults $(N=85,088)$. Mental disorders were assessed with the Composite International Diagnostic Interview. Pain was assessed by self-report. Both multiple and single site pain problems were associated with mood and anxiety disorders, but not with alcohol abuse or dependence. In general, the prevalence of specific mood and anxiety disorders followed a linear pattern with the lowest rates found among persons with no pain, intermediate rates among those with one pain, and highest rates among those with multi-site pain problems. Relative to persons not reporting pain, the pooled estimates of the age-sex adjusted odds ratios were 1.8 (1.7-2.0) for mood disorders and 1.9 (1.8-2.1) for anxiety disorders for persons with single site pain; 3.7 (3.3-4.1) for mood disorders and 3.6 (3.3-4.0) for anxiety disorders among
\end{abstract}

\footnotetext{
${ }^{*}$ Corresponding author. Tel.: +234 22410146.

E-mail address: ogureje@comui.edu.ng (O. Gureje).
} 
those with multi-site pain. Our results indicate that the presence of multiple pain conditions was strongly and comparably associated with mood and anxiety disorders in diverse cultures. This consistent pattern of associations suggests that diffuse pain and psychiatric disorders are generally associated, rather than diffuse pain representing an idiom for expressing distress that is specific to particular cultural settings or diffuse pain solely representing a form of masked depression.

(C) 2007 International Association for the Study of Pain. Published by Elsevier B.V. All rights reserved.

Keywords: Multiple pains; Depression; Anxiety; Alcohol abuse; Cross national

\section{Introduction}

Chronic pain is often comorbid with psychiatric disorders, with depression having received the most attention to date (Magni and Moreschi, 1994; Fishbain and Cutler, 1997; Gureje and Von Korff, 1998; McWilliams and Cox, 2003). Understanding the relationship between chronic pain and psychiatric disorders is important. Several studies have suggested that chronic pain patients with coexisting psychiatric disorders have poorer treatment outcomes and increased disability (Gatchel, 1996; Holzberg and Robinson, 1996; Burns and Johnson, 1998; Dersh and Polatin, 2002).

Pain problems at different anatomical sites tend to co-occur (Hestbaek and Leboeuf-Yde, 2003; Von Korff and Crane, 2005) and it has been observed that persons who report multiple pain conditions are more likely to experience depressive illness (Dworkin and Von Korff, 1990; Yap and Chua, 2002). Dworkin et al. found elevated risk of major depression among persons with two or more pains while those with one pain condition were no different from persons with no pain (Dworkin and Von Korff, 1990). In this study, the number of pain sites was a better predictor of the co-occurrence of major depression than was pain severity or pain persistence. They suggested that multiple pain conditions might be a variant of somatization disorder, a syndrome of diverse medically unexplained physical symptoms frequently associated with depression (Barsky, 1979; Katon and Kleinman, 1981). From this perspective, the distinction between persons with pain at single versus multiple anatomical locations is significant in understanding the relationship between chronic pain conditions and psychiatric disorders (Fishbain and Cutler, 1997).

Most previous studies of the association of psychiatric disorders with chronic pain have focused on depression (Bair and Robinson, 2003; Ohayon and Schatzberg, 2003). It is therefore unclear whether the suggestion that chronic pain may be a variant of depression or masked depression (Magni and De Bertolini, 1983; Turk and Salovey, 1984; Ohayon and Schatzberg, 2003) is real or instead reflects a paucity of data in regard to the association of chronic pain with other psychiatric conditions. For example, only a few studies have examined the relationship of pain with anxiety disorders and the results have been inconsistent (Atkinson and Slater, 1991; McWilliams and Cox, 2003; McWilliams and Goodwin, 2004).

Previous studies of the relationship between chronic pain and psychiatric disorders have largely been conducted in Western Europe and North America. Given the suggestion that the association between somatic symptoms, including pain conditions, and psychiatric illness may be influenced by cultural factors (Kleinman and Kleinman, 1985), the generalizability of these findings to non-Western populations is an important question.

In this report, we aim to determine whether: (1) persons with pain at multiple anatomical sites have higher rates of specific mood, anxiety, and alcohol use disorders compared to persons with single site pain or with no pain problems; (2) the strength of association of multiple pain conditions differs for specific anxiety disorders from those observed for mood disorders; and, (3) the pattern of association of number of pain problems and mental disorders differs across diverse populations world-wide, including populations in both developed and developing countries.

\section{Methods}

\subsection{Samples}

The World Mental Health Surveys consist of communitybased studies conducted in many countries around the world. The present report is based on data obtained from 18 surveys carried out in 17 countries in the Americas (Colombia, Mexico, United States), Europe (Belgium, France, Germany, Italy, Netherlands, Spain, Ukraine), the Middle East/Africa (Israel, Lebanon, Nigeria, South Africa), and Asia and the South Pacific (Japan, separate surveys in Beijing and Shanghai in the People's Republic of China, New Zealand). All surveys were based on multi-stage, clustered area probability household samples. All interviews were carried out face-to-face by trained lay interviewers. Sample sizes range from 2372 (the Netherlands) to 13,229 (New Zealand), with a total of 85,088 participating adults. Response rates ranged from $46 \%$ (France) to $88 \%$ (Colombia), with a weighted average of $71 \%$.

The questionnaire was composed of two parts: Part 1 consisted of sections that allowed for the diagnostic assessment of a range of mental disorders while Part 2 consisted of sections focusing on antecedents and correlates of mental disorders, including comorbid physical conditions. The assessment of chronic pain conditions was included in Part 2. All respondents completed part 1. All part-1 respondents who met 
criteria for any mental disorder and a probability sample of other respondents were administered part 2. Part-2 respondents were weighted by the inverse of their probability of selection for part-2 of the interview to adjust for differential sampling. Analyses in this article were based on the weighted part-2 sample. Additional weights were used to adjust for differential probabilities of selection within households and to match the samples to population socio-demographic distributions. The samples thus reflect the expected population age and social structure of the countries with younger age and lower educational status being more characteristic of the less developed countries.

\subsection{Training and field procedures}

The central World Mental Health (WMH) staff trained bilingual supervisors in each country. Consistent interviewer training documents and procedures were used across surveys. The WHO translation protocol was used to translate instruments and training materials. Two surveys were carried out in bilingual form (Dutch and French in Belgium; Russian and Ukrainian in Ukraine). Others were carried out exclusively in the country's official language. In Nigeria, interviews were conducted in the four languages (Yoruba, Hausa, Igbo, and Efik) spoken in the regions where the survey was carried out. In South Africa, six different languages were used: English, Afrikaans, Zulu, Xhosa, Northen Soho, and Tswana. Standardized descriptions of the goals and procedures of the study, data uses and protection and the rights of respondents were provided in both written and verbal form to all potentially eligible respondents before obtaining verbal informed consent for participation in the survey. Quality control protocols, described in more detail elsewhere (Kessler and Ustun, 2004), were standardized across countries to check on interviewer accuracy and to specify data cleaning and coding procedures. All surveys were conducted strictly in compliance with procedures approved by the local Institutional Review Board applicable in the respective country.

\subsection{Mental disorder status}

All surveys used the World Mental Health Survey version of the WHO Composite International Diagnostic Interview (WMH-CIDI; Kessler and Ustun, 2004), a fully structured diagnostic interview, to assess disorders and treatment. Disorders considered in this paper include anxiety disorders (generalized anxiety disorder, panic disorder and/or agoraphobia, posttraumatic stress disorder, and social phobia), mood disorders (dysthymia and major depressive disorder), and substance disorders (alcohol abuse and dependence). Disorders were assessed using the definitions and criteria of the Diagnostic and Statistical Manual of Mental Disorders, Fourth Edition (DSM-IV) (American Psychiatric Association, 1994). CIDI organic exclusion rules were applied in making all diagnoses. Methodological evidence collected in the WHO-CIDI Field Trials and later clinical calibration studies showed that all the disorders considered herein were assessed with acceptable reliability and validity both in the original CIDI (Wittchen, 1994) and in the original version of the WMH-CIDI (Kessler and Ustun, 2004).

\subsection{Pain}

Each survey asked about the presence of chronic physical conditions using an adaptation of the questions in the U.S Health Interview Survey [Nation Center for Health Statistics, 1994]. Included were questions about chronic pains. We inquired about four chronic pain conditions as well as 15 chronic medical conditions. In regard to the pain conditions, each respondent was asked about whether they experienced chronic back or neck problems, arthritis or rheumatism, frequent or severe headaches, or any other pain problem in the prior 12 months. (For example, for back and neck pains: "Have you had chronic back or neck problems in the past 12 months"?) The question about arthritis was asked in two different forms depending on country. In Nigeria, Lebanon, Beijing, Shanghai and the Ukraine, respondents were asked whether they had experienced "arthritis or rheumatism" in the prior 12 months. In the remaining surveys, respondents were asked if they had ever had "arthritis or rheumatism", with the assumption made that arthritis that has been present in the past will also be present in the prior year. ("Have you ever in your lifetime experienced arthritis or rheumatism?") The number of pain sites was determined by counting the number of pain problems (with a possible total of 4 : back/neck pain, headaches, arthritis, other pain) present in the prior 12 months.

\subsection{Analysis methods}

This paper reports 12-month prevalence rates for specific mental disorders among persons with 1 and those with 2 or more pain conditions during the prior year. Logistic regression was used to assess the association of number of pain conditions with mental disorder status after adjusting for age and sex. In the analyses for specific mental disorders, number of pain conditions was entered as a continuous variable due to sparse cell sizes for some mental disorders. For each survey and specific mental disorder, a $t$-test was used to assess whether the beta coefficient for number of pain conditions was significantly greater than zero. The regression models were estimated using the Taylor Series method (Wolter, 1985) with SUDAAN software (SUDAAN 2002) which take into account the complex survey design. There were wide variations in mental disorder prevalence rates, and in prevalence rates of the pain conditions, across the surveys. For this reason, this report does not include pooled estimates of mental disorder or chronic pain prevalence rates.

We estimated adjusted odds ratios to assess the association of any mood disorder (major depressive disorder or dysthymia) and of any anxiety disorder (generalized anxiety disorders, panic/agoraphobia, social phobia, or post-traumatic stress disorder) with one and with multiple pain conditions, respectively. A pooled estimate of these odds ratios across surveys was also estimated. These odds ratios, and the pooled estimate and its confidence intervals, are displayed for each survey using a funnel graph (Bird and Cox, 2005). This graph plots the odds ratio for each survey on a log scale ( $y$-axis) against the precision of the estimate of each odds ratio ( $x$-axis). Precision is the reciprocal of the standard error of the odds ratio estimate. Precision increases as the standard error of the estimate becomes smaller. The "funnel" in these graphs shows 
the $95 \%$ confidence interval band for a survey estimate that would include the pooled estimate of the odds ratio at varying levels of precision. Each survey's estimate was plotted on the funnel graph, showing whether the $95 \%$ confidence interval of each estimate includes the pooled estimate of the odds ratio, given the estimated precision of that survey's estimate. On this graph, the less precise estimates are to the left (where the funnel is wider), and the more precise estimates are to the right (where the funnel is narrower). The association of the presence of any mood disorder and of any anxiety disorder with one or multiple pain conditions was tested using odds ratio. We assessed whether the heterogeneity of the estimates of the odds ratio across surveys was greater than expected by chance (DerSimonian and Laird, 1986). If the heterogeneity of the odds ratios is greater than expected by chance, then pooled estimates have large degrees of imprecision. We found this to be the case for three of the possible four combinations, the exception being the association between any mood and multiple pain conditions. These pooled estimates are therefore only indicative and should be interpreted with caution. We did not estimate odds ratios or do funnel plots for any alcohol abuse/dependence due to small cell sizes.

\section{Results}

Table 1 shows the sample characteristics and the prevalence rates of single and multiple pains across the surveys. Table 2 presents the prevalence of mood disor- ders (major depression and dysthymia) among persons with no pain, one pain, and those with pain at 2 or more sites. Typically, the prevalence of major depressive disorder was lowest among persons with no pain, intermediate among those with one pain, and highest among those with 2 or more pains. This trend was statistically significant in all 18 surveys. A similar pattern was observed for dysthymia. (Dysthymia was not assessed in the South African survey). The trend was significant for 16 of the 17 other surveys.

Fig. 1a and $\mathrm{b}$ are funnel graphs depicting the odds ratios for any mood disorder (major depression or dysthymia) for persons with one pain (Fig. 1a) and two or more pains (Fig. 1b) versus those with no pain. These graphs show that the pooled estimate of the odds ratio of having a mood disorder for those with one pain versus those not reporting pain was about 1.8 , reflecting a significant association between pain and mood disorder. The $95 \%$ confidence intervals of all but three of the odds ratio estimates included the pooled estimate across the 18 surveys (the exceptions being Mexico, Japan and New Zealand). When compared to Fig. 1b which displays the odds ratios for mood disorder for persons with 2 or more pains versus those with no pain, it can be seen that the pooled estimate of the odds ratio for two or more pains (relative to no pains) is about double (3.7).

Table 1

Sample characteristics, and number of pains prevalence

\begin{tabular}{|c|c|c|c|c|c|c|c|c|c|}
\hline \multirow[t]{3}{*}{ Country } & \multirow{3}{*}{$\begin{array}{l}\text { National } \\
\text { sample }(N)\end{array}$} & \multirow{3}{*}{$\begin{array}{l}\text { Mean } \\
\text { age }^{\text {a }}\end{array}$} & \multirow{3}{*}{$\begin{array}{l}\% 60 \text { years } \\
\text { or older }\end{array}$} & \multirow[t]{3}{*}{$\%$ women } & \multirow{3}{*}{$\begin{array}{l}\text { Education } \\
\text { Secondary } \\
\text { or greater }\end{array}$} & \multicolumn{4}{|c|}{ Number of pains prevalence ${ }^{b}$} \\
\hline & & & & & & \multicolumn{2}{|c|}{ One pain } & \multicolumn{2}{|c|}{ Two or more pains } \\
\hline & & & & & & $\mathrm{N}$ & $\mathrm{Wt} \%$ & $N$ & $\mathrm{Wt} \%$ \\
\hline \multicolumn{10}{|l|}{ America } \\
\hline Colombia & 2381 & 36.6 & 5.3 & 54.5 & 46.4 & 581 & 21.3 & 224 & 6.0 \\
\hline Mexico & 2362 & 35.2 & 5.2 & 52.3 & 31.4 & 517 & 17.9 & 218 & 6.2 \\
\hline United States & 5692 & 45.0 & 21.2 & 53.0 & 83.2 & 1644 & 27.8 & 1144 & 16.1 \\
\hline \multicolumn{10}{|c|}{ Asia and South Pacific } \\
\hline Japan & 887 & 51.4 & 34.9 & 53.7 & 70.0 & 208 & 20.2 & 112 & 7.9 \\
\hline PRC-Beijing & 914 & 39.8 & 15.6 & 47.5 & 61.4 & 251 & 23.8 & 163 & 13.2 \\
\hline PRC-Shanghai & 714 & 42.9 & 18.7 & 48.1 & 46.8 & 165 & 20.9 & 118 & 13.6 \\
\hline New Zealand & 7312 & 44.6 & 20.7 & 52.2 & 60.4 & 1971 & 25.9 & 1187 & 13.2 \\
\hline \multicolumn{10}{|l|}{ Europe } \\
\hline Belgium & 1043 & 46.9 & 27.3 & 51.7 & 69.7 & 267 & 25.8 & 181 & 14.6 \\
\hline France & 1436 & 46.3 & 26.5 & 52.2 & NA & 489 & 35.0 & 272 & 14.6 \\
\hline Germany & 1323 & 48.2 & 30.6 & 51.7 & 96.4 & 328 & 22.1 & 149 & 10.4 \\
\hline Italy & 1779 & 47.7 & 29.2 & 52.0 & 39.5 & 473 & 25.3 & 398 & 20.2 \\
\hline Netherlands & 1094 & 45.0 & 22.7 & 50.9 & 69.7 & 276 & 20.7 & 173 & 12.5 \\
\hline Spain & 2121 & 45.5 & 25.5 & 51.4 & 41.7 & 582 & 24.6 & 356 & 10.3 \\
\hline Ukraine & 1720 & 46.1 & 27.3 & 55.1 & 79.5 & 422 & 26.4 & 768 & 33.9 \\
\hline \multicolumn{10}{|c|}{ Middle East and Africa } \\
\hline Lebanon & 602 & 40.3 & 15.3 & 48.1 & 40.5 & 114 & 15.9 & 80 & 10.5 \\
\hline Nigeria & 2143 & 35.8 & 9.7 & 51.0 & 35.6 & 414 & 16.8 & 369 & 13.6 \\
\hline Israel & 4859 & 44.4 & 20.3 & 51.9 & 78.3 & 1033 & 21.2 & 609 & 12.3 \\
\hline South Africa & 4315 & 37.1 & 8.8 & 53.6 & 38.9 & 1090 & 25.5 & 1027 & 22.8 \\
\hline
\end{tabular}

${ }^{a}$ Age range $\geqslant 18$, except for Colombia, Mexico (18-65), Japan $(\geqslant 20)$ and Israel $(\geqslant 21)$.

b Number of pains based on arthritis, headache, back pain and other chronic pain. Headache, back pain and other pain prevalence based on last 12 months; arthritis prevalence based on lifetime except for Beijing, Shanghai, Lebanon, Nigeria, Ukraine and South Africa (12 month prevalence). 
Table 2

Prevalence $(\%)$ of mood disorders among persons with 0,1 and $2+$ pains

\begin{tabular}{|c|c|c|c|c|c|c|c|c|c|c|}
\hline \multirow[t]{2}{*}{ Country } & \multicolumn{5}{|c|}{ Major depression } & \multicolumn{5}{|c|}{ Dysthymia } \\
\hline & No pains & 1 pain & $2+$ pains & Beta & $P$ value & No pains & 1 pain & $2+$ pains & Beta & $P$ value \\
\hline Colombia & 4.3 & 8.6 & 19.6 & 0.705 & 0.001 & 0.8 & 1.2 & 3.7 & 0.647 & 0.010 \\
\hline Mexico & 2.4 & 8.5 & 12.7 & 0.810 & 0.001 & 0.6 & 1.5 & 2.7 & 0.630 & 0.001 \\
\hline United States & 5.5 & 8.5 & 17.6 & 0.652 & 0.001 & 1.1 & 2.1 & 6.9 & 0.812 & 0.001 \\
\hline Japan & 2.0 & 1.4 & 7.1 & 0.517 & 0.003 & 0.7 & 0.1 & 2.7 & 0.544 & 0.083 \\
\hline Beijing & 1.3 & 3.5 & 5.6 & 0.793 & 0.001 & 0.1 & 0.8 & 0.7 & 0.727 & 0.010 \\
\hline Shanghai & 0.8 & 0.5 & 7.7 & 1.332 & 0.001 & 0.3 & 0.5 & 0.3 & 0.143 & 0.628 \\
\hline New Zealand & 5.4 & 6.3 & 12.6 & 0.547 & 0.001 & 1.3 & 1.8 & 4.4 & 0.609 & 0.001 \\
\hline Belgium & 4.1 & 7.1 & 9.2 & 0.459 & 0.003 & 0.7 & 1.8 & 2.8 & 0.523 & 0.021 \\
\hline France & 4.5 & 6.2 & 11.1 & 0.544 & 0.001 & 1.0 & 1.8 & 3.4 & 0.496 & 0.033 \\
\hline Germany & 2.3 & 4.2 & 5.7 & 0.642 & 0.001 & 0.4 & 1.5 & 3.0 & 1.027 & 0.001 \\
\hline Italy & 2.0 & 2.8 & 6.6 & 0.514 & 0.001 & 0.6 & 1.1 & 2.3 & 0.404 & 0.016 \\
\hline Netherlands & 3.9 & 7.8 & 8.3 & 0.433 & 0.001 & 1.2 & 2.5 & 3.6 & 0.584 & 0.006 \\
\hline Spain & 2.8 & 4.7 & 10.6 & 0.621 & 0.001 & 0.6 & 1.8 & 5.0 & 0.735 & 0.001 \\
\hline Ukraine & 4.0 & 7.1 & 17.7 & 0.522 & 0.000 & 0.6 & 3.4 & 8.9 & 0.640 & 0.001 \\
\hline Lebanon & 1.2 & 4.3 & 2.6 & 0.547 & 0.024 & 0.3 & 2.3 & 1.5 & 0.785 & 0.013 \\
\hline Nigeria & 0.8 & 1.3 & 2.8 & 0.515 & 0.001 & 0.1 & 0.1 & 1.0 & 0.857 & 0.003 \\
\hline Israel & 4.1 & 8.4 & 13.1 & 0.537 & 0.001 & 0.5 & 1.5 & 4.9 & 0.830 & 0.001 \\
\hline South Africa & 3.1 & 4.8 & 8.9 & 0.406 & 0.001 & 0.0 & 0.0 & 0.0 & - & $\mathrm{NE}$ \\
\hline
\end{tabular}

NE, non-estimable.

These figures show that single pain problems are associated with depressive illness, but that multiple pain conditions show a substantially stronger relationship with depression. The test of heterogeneity of the pain status-depression odds ratios across the 18 surveys was non-significant for persons with two or more pain problems $(P=0.52)$. However, there was greater variability in the odds ratios for the relationship between having pain at a single site and depression than would be expected on the basis of chance $(P=0.03)$.

The associations of specific anxiety disorders with number of pain sites are displayed in Table 3 . The surveys showed a similar pattern for anxiety disorders as that observed for depression, with the prevalence of specific anxiety disorders increasing with the number of pain sites. However, the pattern of association of anxiety disorders was less consistent, possibly because the lower prevalence rates of the specific anxiety disorders resulted in less stable estimates. The number of surveys in which statistically significant $(P<0.05)$ or borderline significant $(P<0.10)$ associations were found between number of pain problems and anxiety disorder was 16 of 17 for generalized anxiety disorder, 13 of 16 for panic disorder/agoraphobia, 11 of 16 for social phobia, and 11 of 17 for post-traumatic stress disorder.

Funnel graphs show the odds ratios, adjusted for sex and age, for anxiety disorder (as a group) among persons with one pain disorder (Fig. 2a) and those with 2 or more pains (Fig. 2b) compared to those with no pain. The combined anxiety disorder category shows a clearer pattern of association with multiple pains than the individual anxiety disorders, likely due to the larger number of cases available for analyses. The pooled estimate of the odds ratio for persons with multi-site pain (vs. no pain) was 3.6, while the odds ratio was 1.9 for persons with single pain (vs. no pain). The $95 \%$ confidence intervals of the individual survey estimates typically included the pooled estimate. There was no greater variation than expected by chance in the odds ratios for the pain-anxiety disorder relationship for both persons with one pain problem $(P=0.08)$, but there was significant heterogeneity in the odds ratios for multi-site pain problems $(P=0.003)$.

Table 4 shows the prevalence of alcohol abuse or dependence among persons with no pain, pain at a single site, and for pain at multiple sites. Unlike mood and anxiety disorders, this table shows no clear pattern between alcohol abuse/dependence and the number of pain sites. Indeed, among the five surveys in which there was a significant association between number of pain sites and the prevalence of alcohol abuse/dependence $(P \leqslant 0.05)$, a linear increase in the prevalence of alcohol abuse with number of pain problems was only observed in one survey.

\section{Discussion}

In this report, we have used data from 18 population surveys participating in the World Mental Health Survey Initiative to explore the relationships between pain at one or multiple anatomic sites with specific mood and anxiety disorders. Our research provides the first general population data addressing these relationships from both developed and developing countries. Prior research suggests that as the number of pain problems reported increases, the prevalence of depressive illness 


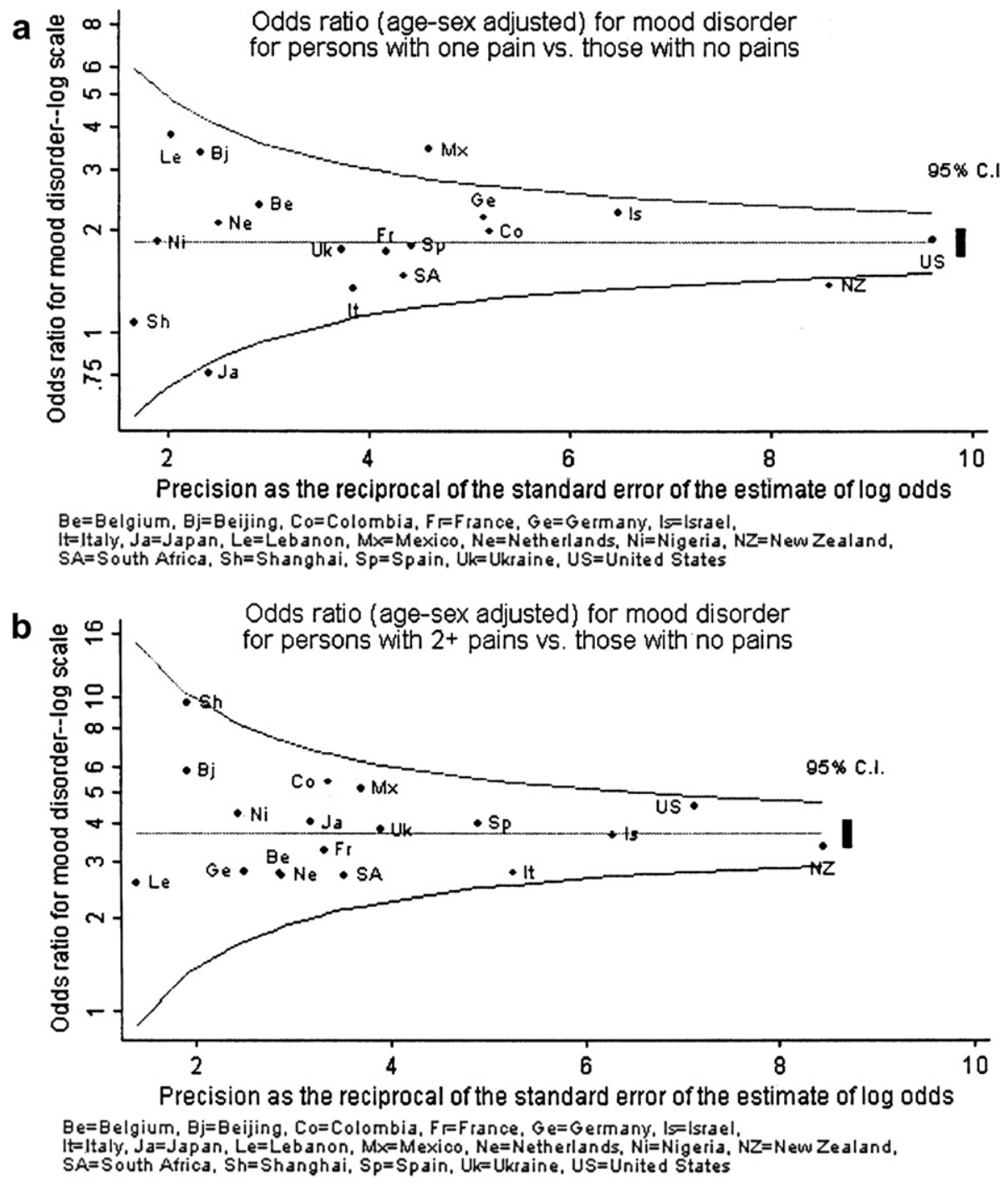

Fig. 1. (a) Odds ratio (age-sex adjusted) for mood disorder for persons with one pain vs. those with no pains. (b) Odds ratio (age-sex adjusted) for mood disorder for persons with +2 pains vs. those with no pains.

also increases. This report shows, for the first time, that this relationship is observed in general population samples in diverse countries world-wide. The results of these surveys also show that this relationship applies for four different anxiety disorders: panic disorder, generalized anxiety disorder, social phobia and post-traumatic stress disorder. Rates of depressive illness and anxiety disorders were elevated both among persons with a single pain problem, and persons reporting multiple pain conditions, but the association was substantially stronger for persons with multi-site pain.

Previous studies have shown that chronic pain constitutes a major public health problem. Estimates vary, depending on the survey and on the anatomical site of interest, but community surveys conducted in Western Europe and North America have reported that as many as $25-50 \%$ of the adult population may suffer from some form of chronic pain (Bovim and Schrader, 1994; Rajala and Keinanen-Kiukaanniemi, 1995; Palmer and Walsh, 2000; Santos-Eggiman and Wietlisbach, 2000; Picavet and Schouten, 2003; Von Korff and Crane, 2005). The results of the World Mental Health Surveys also show that chronic pain problems are common world-wide, in both developed and developing countries.

The association of chronic pain with depression has been widely reported (Von Korff and Simon, 1996; Fishbain and Cutler, 1997; Currie and Wang, 2004). The association of pain with anxiety disorders is less studied and findings have been less consistent. Our results provide evidence in support of an association between chronic pain and anxiety disorders as well as the first large cross-national evidence that the association of chronic pain with both mood and anxiety disorders extends to non-Western countries. The notion that chronic pain is a variant of depression (Blumer and Heilbronn, 1982), or is a depressive equivalent or 
Table 3

Prevalence $(\%)$ of anxiety disorders among persons with 0,1 and $2+$ pains

\begin{tabular}{|c|c|c|c|c|c|c|c|c|c|c|}
\hline \multirow[t]{2}{*}{ Country } & \multicolumn{5}{|c|}{ Generalized anxiety } & \multicolumn{5}{|c|}{ Agoraphobia or panic disorder } \\
\hline & No pains & 1 pain & $2+$ pains & Beta & $P$ value & No pains & 1 pain & $2+$ pains & Beta & $P$ value \\
\hline Colombia & 0.8 & 1.6 & 1.3 & 0.441 & 0.059 & 1.9 & 3.0 & 5.3 & 0.382 & 0.030 \\
\hline Mexico & 0.3 & 1.2 & 1.6 & 0.740 & 0.001 & 0.9 & 1.6 & 6.3 & 0.771 & 0.001 \\
\hline United States & 2.2 & 4.4 & 9.9 & 0.680 & 0.001 & 2.4 & 3.6 & 8.0 & 0.611 & 0.001 \\
\hline Japan & 1.0 & 2.2 & 4.9 & 0.661 & 0.001 & 0.3 & 0.7 & 4.2 & 1.110 & 0.001 \\
\hline Beijing & 0.3 & 2.4 & 2.4 & 0.622 & 0.001 & 0.1 & 0.5 & 1.4 & 0.918 & 0.050 \\
\hline Shanghai & 0.1 & 0.3 & 4.6 & 2.039 & 0.001 & 0.0 & 0.0 & 0.9 & - & $\mathrm{NE}$ \\
\hline New Zealand & 1.9 & 2.9 & 8.3 & 0.746 & 0.001 & 1.6 & 2.0 & 5.8 & 0.716 & 0.001 \\
\hline Belgium & 0.4 & 1.5 & 2.8 & 0.849 & 0.003 & 1.6 & 1.4 & 1.6 & 0.367 & 0.209 \\
\hline France & 1.2 & 2.3 & 4.5 & 0.719 & 0.001 & 1.4 & 2.1 & 1.7 & 0.232 & 0.282 \\
\hline Germany & 0.3 & 0.8 & 1.2 & 0.751 & 0.007 & 0.8 & 1.5 & 1.8 & 0.480 & 0.030 \\
\hline Italy & 0.4 & 0.3 & 1.0 & 0.302 & 0.338 & 0.5 & 1.4 & 2.1 & 0.539 & 0.002 \\
\hline Netherlands & 0.4 & 2.3 & 2.5 & 0.791 & 0.001 & 1.3 & 2.3 & 2.6 & 0.306 & 0.141 \\
\hline Spain & 0.8 & 0.8 & 2.8 & 0.616 & 0.001 & 0.4 & 1.0 & 2.7 & 0.804 & 0.001 \\
\hline Ukraine & 0.5 & 1.2 & 5.3 & 0.765 & 0.001 & 0.4 & 1.4 & 4.0 & 0.619 & 0.001 \\
\hline Lebanon & 0.1 & 0.4 & 0.7 & 0.742 & 0.009 & 0.2 & 0.2 & 0.2 & - & $\mathrm{NE}$ \\
\hline Nigeria & 0.0 & 0.0 & 0.2 & - & $\mathrm{NE}$ & 0.1 & 0.0 & 1.4 & 1.034 & 0.001 \\
\hline Israel & 1.4 & 4.5 & 6.3 & 0.666 & 0.001 & 0.4 & 1.6 & 2.5 & 0.725 & 0.001 \\
\hline \multirow[t]{3}{*}{ South Africa } & 1.1 & 1.7 & 4.0 & 0.521 & 0.001 & 3.7 & 6.7 & 8.8 & 0.335 & 0.001 \\
\hline & \multicolumn{5}{|c|}{ Social phobia } & \multicolumn{5}{|l|}{ PTSD } \\
\hline & No pains & 1 pain & $2+$ pains & Beta & $P$ value & No pains & 1 pain & $2+$ pains & Beta & $P$ value \\
\hline Colombia & 2.3 & 4.6 & 5.1 & 0.467 & 0.000 & 0.4 & 1.0 & 1.1 & 0.345 & 0.168 \\
\hline Mexico & 1.3 & 3.5 & 7.8 & 0.874 & 0.001 & 0.3 & 1.4 & 1.2 & 0.681 & 0.001 \\
\hline United States & 5.8 & 7.4 & 11.7 & 0.438 & 0.001 & 1.9 & 3.8 & 9.1 & 0.732 & 0.001 \\
\hline Japan & 0.5 & 0.9 & 1.5 & 0.551 & 0.111 & 0.4 & 0.4 & 0.4 & 0.048 & 0.888 \\
\hline Beijing & 0.3 & 0.2 & 0.6 & 0.363 & 0.368 & 0.2 & 0.2 & 0.9 & 0.678 & 0.240 \\
\hline Shanghai & 0.0 & 0.0 & 0.0 & - & $\mathrm{NE}$ & 0.0 & 0.3 & 0.4 & 1.446 & 0.015 \\
\hline New Zealand & 4.5 & 5.8 & 7.9 & 0.420 & 0.001 & 1.8 & 3.6 & 7.5 & 0.701 & 0.001 \\
\hline Belgium & 1.0 & 0.5 & 3.6 & 0.721 & 0.010 & 0.4 & 0.5 & 2.1 & 0.899 & 0.042 \\
\hline France & 2.8 & 3.2 & 1.4 & -0.042 & 0.841 & 1.3 & 2.8 & 4.6 & 0.565 & 0.001 \\
\hline Germany & 1.1 & 4.2 & 1.1 & 0.527 & 0.004 & 0.6 & 0.4 & 1.7 & 0.426 & 0.200 \\
\hline Italy & 0.8 & 1.3 & 2.1 & 0.379 & 0.025 & 0.4 & 1.2 & 1.0 & 0.458 & 0.149 \\
\hline Netherlands & 0.8 & 2.0 & 2.4 & 0.557 & 0.003 & 0.9 & 3.6 & 9.0 & 0.663 & 0.001 \\
\hline Spain & 0.5 & 0.9 & 1.5 & 0.873 & 0.001 & 0.3 & 0.3 & 2.3 & 0.939 & 0.001 \\
\hline Ukraine & 1.3 & 2.4 & 2.8 & 0.545 & 0.004 & 0.6 & 2.9 & 5.1 & 0.509 & 0.001 \\
\hline Lebanon & 0.6 & 0.7 & 0.0 & -0.464 & 0.642 & 0.8 & 3.0 & 6.0 & 0.781 & 0.119 \\
\hline Nigeria & 0.3 & 0.0 & 0.2 & -0.227 & 0.809 & 0.0 & 0.0 & 0.0 & - & $\mathrm{NE}$ \\
\hline Israel & NA & NA & NA & - & NA & 0.3 & 0.8 & 1.5 & 0.686 & 0.001 \\
\hline South Africa & 1.3 & 2.2 & 3.0 & 0.483 & 0.001 & 0.3 & 0.5 & 1.4 & 0.691 & 0.002 \\
\hline
\end{tabular}

NE, non-estimable; NA, data not available.

masked depression (Magni and De Bertolini, 1983), is not consistent with our findings, as anxiety disorders showed a comparable level of association with pain at single and multiple anatomic sites. That is, chronic pain condition, either in single or multiple anatomic sites, is no less related to anxiety than it is to depression.

Compared to persons with one pain condition, those with multiple pains had almost double the likelihood of having both mood and anxiety disorders. This observation differs from that reported by Dworkin and Von Korff, 1990. They found an elevated risk of algorithm diagnosis of major depression for persons with multiple pains, found no difference between those with one and those with no pain condition. Our findings, based on representative population samples from widely divergent national and cultural settings, are inconsistent with those observations. Rather, our findings suggest that multiple pain conditions are more strongly associated with psychiatric disorder, but pain at a single anatomical site was also significantly associated with psychiatric disorders. Our data suggest that the presence of one chronic pain condition increases the likelihood of cooccurring psychiatric disorder and that the risk is further elevated when pain at multiple sites is present.

The surveys reported in this paper were cross-sectional and cannot provide information on the direction of causality between pain and psychiatric disorders. There is indeed evidence for a bi-directional relationship between pain and psychopathology. In a 1-year longitudinal follow-up, Gureje et al. reported that persistent pain at baseline predicted new onset of depression over 12 months and vice versa (Gureje and Simon, 2001). We can therefore only speculate on the possible routes by which the associations between pain and psychiatric 
a

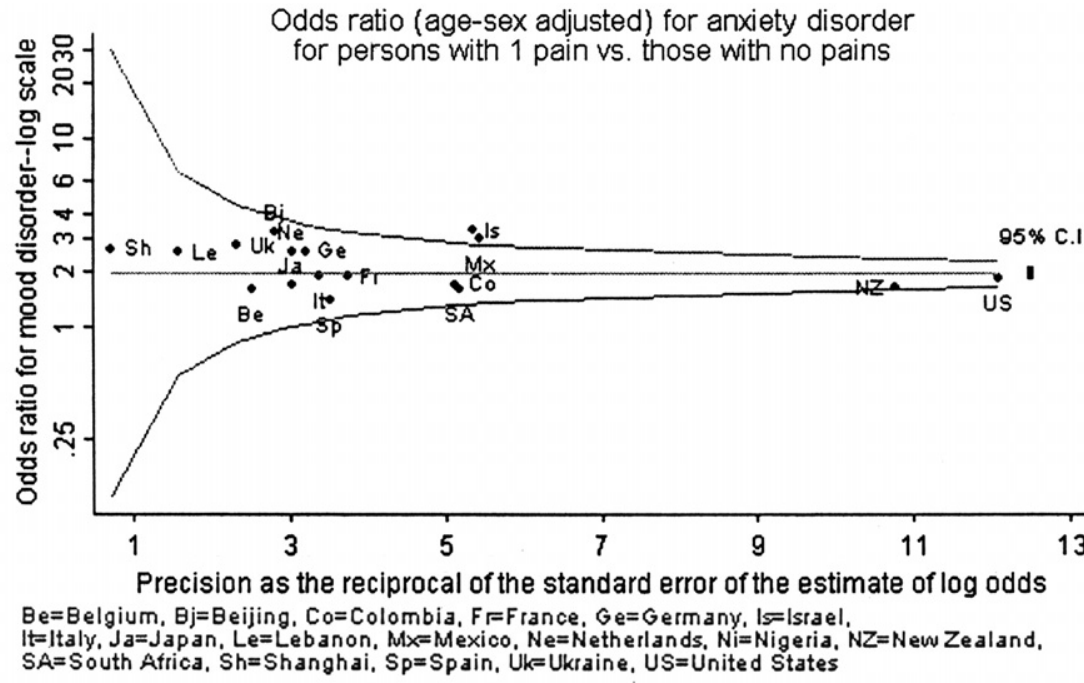

b

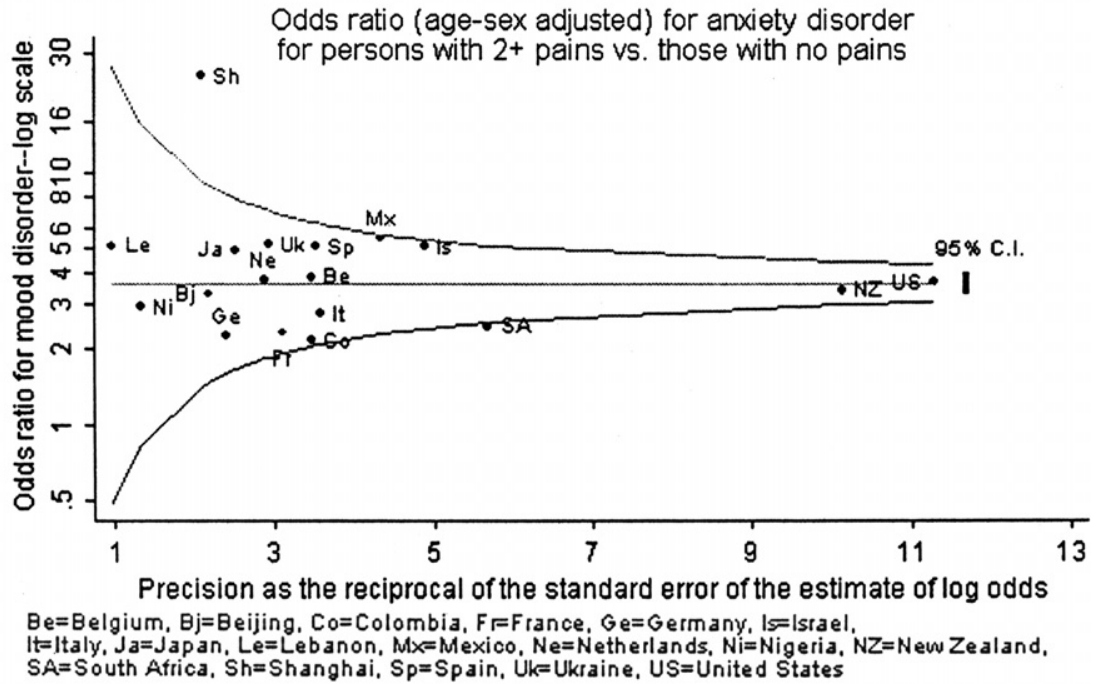

Fig. 2. (a) Odds ratio (age-sex adjusted) for anxiety disorder for persons with 1 pain vs. those with no pains. (b) Odds ratio (age-sex adjusted) for anxiety disorder for persons with +2 pains vs. those with no pains.

disorders are established. Some have speculated that a finding of a higher occurrence of psychiatric disorders among persons with multiple pains relative to those with one pain might indicate that chronic pains precede psychiatric disorders (Fishbain and Cutler, 1997). There is some evidence that persons with multiple pain conditions are less likely to recover from their pains over a 12month period than those with single pains (Gureje and Simon, 2001). Thus, if the likelihood of psychiatric disorders occurring is increased with persistence of pain, persons with multiple pains may be expected to experience more psychiatric disorders. There is however also the possibility, as has been suggested for migraine (Breslau and Davis, 1993), that certain pain conditions share a common predisposition with some psychiatric disorders.

Our findings are consistent with a view that pain and psychiatric disorders, especially depression and anxiety disorders, are commonly associated across diverse cultural settings. Even though this consistent association could be interpreted to mean a lack of support for the claim that diffuse pain represents an idiom for expressing distress in particular cultural settings, our study is specific to chronic pain and was not designed to examine the psychological or somatic response to stress. However, evidence from other large studies suggests that the association between diverse somatic complaints, not just pain, and common psychiatric disorders does not support specific and unique cultural patterning (Gureje and Ustun, 1997).

Our results are based on very large datasets collected from a broad range of countries. However, and as stated in Methods, there was a wide variability in the strength of the association of mood and anxiety disorders with multiple pain conditions. The resulting significant heterogeneity of the estimates of the odds ratio across countries limits the precision of the pooled estimates. The results of those pooled estimates therefore require some caution in their interpretation. Also, we assessed pain 
Table 4

Prevalence $(\%)$ of alcohol use disorders among persons with 0,1 and $2+$ pains

\begin{tabular}{|c|c|c|c|c|c|}
\hline \multirow[t]{2}{*}{ Country } & \multicolumn{5}{|c|}{ Alcohol abuse or dependence } \\
\hline & No pains & 1 pain & $2+$ pains & Beta & $P$ value \\
\hline Colombia & 2.6 & 2.8 & 1.9 & 0.343 & 0.095 \\
\hline Mexico & 2.2 & 1.3 & 4.6 & 0.506 & 0.035 \\
\hline United States & 3.5 & 1.8 & 3.9 & 0.348 & 0.001 \\
\hline Japan & 1.0 & 0.7 & 2.9 & 0.500 & 0.298 \\
\hline Beijing & 1.5 & 3.1 & 6.1 & 0.891 & 0.001 \\
\hline Shanghai & 0.5 & 0.1 & 0.5 & 0.128 & 0.833 \\
\hline New Zealand & 2.8 & 2.7 & 3.2 & 0.466 & 0.001 \\
\hline Belgium & 0.8 & 2.3 & 1.5 & 0.663 & 0.012 \\
\hline France & 0.8 & 0.8 & 0.5 & 0.102 & 0.770 \\
\hline Germany & 1.3 & 1.7 & 0.2 & 0.238 & 0.524 \\
\hline Italy & 0.1 & 0.1 & 0.0 & -0.165 & 0.838 \\
\hline Netherlands & 1.8 & 1.3 & 1.7 & 0.130 & 0.629 \\
\hline Spain & 0.5 & 0.0 & 0.0 & - & $\mathrm{NE}$ \\
\hline Ukraine & 8.0 & 6.2 & 4.0 & 0.132 & 0.360 \\
\hline Lebanon & 1.5 & 0.0 & 0.0 & - & $\mathrm{NE}$ \\
\hline Nigeria & 0.6 & 1.1 & 1.0 & - & NE \\
\hline Israel & 0.9 & 2.0 & 1.0 & 0.486 & 0.001 \\
\hline South Africa & 5.6 & 4.5 & 3.8 & -0.025 & 0.752 \\
\hline
\end{tabular}

NE, non-estimable.

conditions using self-reports and with terms such as "frequent", "severe" or "chronic" which could have been interpreted in different ways by our respondents.

In conclusion, we have presented data showing that the presence of chronic pain is associated with mood and anxiety disorders, while persons with multiple pains have a further increase in the risk of mood and anxiety disorder. In contrast, there was no evidence of an association of alcohol abuse/dependence with multiple pain status. It is important to evaluate patients with mood and anxiety disorders for pain, and vice versa, in view of the prevalence of their association, and the availability of treatments that may target each of these sets of symptoms.

\section{Acknowledgements}

The surveys included in this report were carried out in conjunction with the World Health Organization World Mental Health (WMH) Survey Initiative. We thank the WMH staff for assistance with instrumentation, fieldwork, and data analysis. These activities were supported by the United States National Institute of Mental Health (R01MH070884), the John D. and Catherine T. MacArthur Foundation, the Pfizer Foundation, the US Public Health Service (R13-MH066849, R01-MH069864, and R01 DA016558), the Fogarty International Center (FIRCA R01-TW006481), the Pan American Health Organization, Eli Lilly and Company, Ortho-McNeil Pharmaceutical, Inc., GlaxoSmithKline, and Bristol-Myers Squibb. A complete list of WMH publications can be found at http://www.hcp. med.harvard.edu/wmh/. The Mexican National Comorbidity Survey (MNCS) is supported by The National Institute of Psychiatry Ramon de la Fuente (INPRFM-
DIES 4280) and by the National Council on Science and Technology (CONACyT-G30544-H), with supplemental support from the PanAmerican Health Organization (PAHO). The Lebanese survey is supported by the Lebanese Ministry of Public Health, the WHO (Lebanon) and unrestricted grants from Janssen Cilag, Eli Lilly, GlaxoSmithKline, Roche, Novartis and anonymous donations. The ESEMeD project was funded by the European Commission (Contracts QLG5-1999-01042; SANCO 2004123), the Piedmont Region (Italy), Fondo de Investigación Sanitaria, Instituto de Salud Carlos III, Spain (FIS 00/0028), Ministerio de Ciencia y Tecnología, Spain (SAF 2000-158-CE), Departament de Salut, Generalitat de Catalunya, Spain, and other local agencies and by an unrestricted educational grant from GlaxoSmithKline. The Chinese World Mental Health Survey Initiative is supported by the Pfizer Foundation. The Colombian National Study of Mental Health (NSMH) is supported by the Ministry of Social Protection, with supplemental support from the Saldarriaga Concha Foundation. The Israel National Health Survey is funded by the Ministry of Health with support from the Israel National Institute for Health Policy and Health Services Research and the National Insurance Institute of Israel. The World Mental Health Japan (WMHJ) Survey is supported by the Grant for Research on Psychiatric and Neurological Diseases and Mental Health (H13-SHOGAI-023, H14-TOKUBETSU-026, H16-KOKORO-013) from the Japan Ministry of Health, Labour and Welfare. The New Zealand Mental Health Survey (NZMHS) is supported by the New Zealand Ministry of Health, Alcohol Advisory Council, and the Health Research Council. The Nigerian Survey of Mental Health and Wellbeing (NSMHW) is supported 
by the WHO (Geneva), the WHO (Nigeria), and the Federal Ministry of Health, Abuja, Nigeria. The South Africa Stress and Health Study (SASH) is supported by the US National Institute of Mental Health (R01MH059575) and National Institute of Drug Abuse with supplemental funding from the South African Department of Health and the University of Michigan. The Ukraine Comorbid Mental Disorders during Periods of Social Disruption (CMDPSD) study is funded by the US National Institute of Mental Health (RO1MH61905). The US National Comorbidity Survey Replication (NCS-R) is supported by the National Institute of Mental Health (NIMH; U01-MH60220) with supplemental support from the National Institute of Drug Abuse (NIDA), the Substance Abuse and Mental Health Services Administration (SAMHSA), the Robert Wood Johnson Foundation (RWJF; Grant 044708), and the John W. Alden Trust.

\section{References}

American Psychiatric Association (1994). Diagnostic and statistical manual of mental disorders. 4th ed. Washington, DC: American Psychiatric Association.

Atkinson JH, Slater MA, et al. Prevalence, onset, and risk of psychiatric disorders in men with chronic low back pain: a controlled study. Pain 1991;45:111-21.

Bair MJ, Robinson RL, et al. Depression and pain comorbidity: a literature review. Arch Intern Med 2003;163:2433-45.

Barsky AJ. Patients who amplify bodily sensations. Ann Intern Med 1979;91:63-70.

Bird SM, Cox SD, et al. Performance indicators: good, bad, and ugly. J R Stat Soc, A 2005; 168:1-27.

Blumer D, Heilbronn M. Chronic pain as a variant of depressive disease: the pain-prone disorder. J Nerv Ment Dis. 1982;170:381-406.

Bovim G, Schrader H, et al. Neck pain in the general population. Spine 1994;19:1307-9.

Breslau N, Davis GC. Migraine, physical health and psychiatric disorder: a prospective longitudinal study of young adults. J Psychiatr Res 1993;27:211-21.

Burns J, Johnson B, et al. Cognitive and physical capacity process variables predict long-term outcome after treatment of chronic pain. J Consult Clin Psychol 1998;66:434-9.

Currie SR, Wang J. Chronic back pain and major depression in the general Canadian population. Pain 2004;107:60-4.

Dersh J, Polatin PB, et al. Chronic pain and psychopathology: research findings and theoretical considerations. Psychosom Med 2002;64:773-86.

DerSimonian R, Laird N. Meta-analysis in clinical trials. Control Clin Trials 1986;7:177-88.

Dworkin SF, Von Korff M, et al. Multiple pains and psychiatric disturbance. An epidemiologic investigation. Arch Gen Psychiatry 1990;47:239-44.

Fishbain DA, Cutler R, et al. Chronic pain-associated depression: antecedent or consequence of chronic pain? A review. Clin J Pain 1997;13:116-37.

Gatchel RJ. Psychological disorders and chronic pain: cause and effect relationships. In: Gatchel RJ, Turk DC, editors. Psychological approaches to pain management: a practitioner's handbook. New York: Guilford Publications; 1996. p. 33-54.

Gureje O, Simon GE, et al. A cross-national study of the course of persistent pain in primary care. Pain 2001;92:195-200.
Gureje O, Ustun TB, et al. Somatization in cross-cultural perspective: results from a World Health Organization study in primary care. Am J Psychiatry 1997;154:989-95.

Gureje O, Von Korff M, et al. Persistent pain and well-being. A World Health Organization study in primary care. J Am Med Assoc 1998;280:147-51.

Hestbaek L, Leboeuf-Yde C, et al. Is low back pain part of a general health pattern or is it a separate distinct entity? A critical review of comorbidity with low back pain. J. Manipulative Physiol Ther 2003;26:243-52.

Holzberg AD, Robinson ME, et al. The effects of depression and chronic pain on psychosocial and physical functioning. Clin J Pain 1996;12:118-25.

Katon W, Kleinman A, et al. Depression and somatization: a review. Am J Med. 1981;72:127-35.

Kessler RC, Ustun TB. The World Mental Health (WMH) Survey Initiative Version of the World Health Organization (WHO) Composite International Diagnostic Interview (CIDI). Int $\mathbf{J}$ Methods Psychiatr Res 2004;13:93-121.

Kleinman A, Kleinman J. Somatization. In: Kleinman A, Good B, editors. Culture and depression. Berkeley, Calif: University of California Press; 1985.

Magni G, De Bertolini C. Chronic pain as a depressive equivalent. Postgrad Med 1983;73:79-85.

Magni G, Moreschi C, et al. Prospective study on the relationship between depressive symptoms and chronic musculoskeletal pain. Pain 1994;56:289-97.

McWilliams LA, Cox BJ, et al. Mood and anxiety disorders associated with chronic pain: an examination in a nationally representative sample. Pain 2003;106:127-33.

McWilliams LA, Goodwin RD, et al. Depression and anxiety associated with three pain conditions: results from a nationally representative sample. Pain 2004;111:77-83.

National Center for Health Statistics. Evaluation of National Health Interview Survey diagnostic reporting. Vital and Health Statistics 2 1994;120:1-116.

Ohayon MM, Schatzberg AF. Using chronic pain to predict depressive morbidity in the general population. Arch Gen Psychiatry 2003;60:39-47.

Palmer KT, Walsh K, et al. Back pain in Britain: comparison of two prevalence surveys at an interval of 10 years. $\mathrm{Br}$ Med $\mathrm{J}$ 2000;320:1577-8.

Picavet HS, Schouten JS. Musculoskeletal pain the Netherlands: prevalences, consequences and risk groups. The DMC(3)-study. Pain 2003;102:167-78.

Rajala U, Keinanen-Kiukaanniemi S, et al. Musculoskeletal pains and depression in a middle-aged Finnish population. Pain 1995;61:451-7.

Santos-Eggiman B, Wietlisbach V, et al. One-year prevalence of low back pain in two Swiss regions: estimates from the population participating in the 1992-1993 MONICA project. Spine 2000;25:2473-9.

Turk DC, Salovey P. Chronic pain as a variant of depressive disease: a critical reappraisal. J Nerv Ment Dis. 1984;172:398-404.

Von Korff M, Crane P, et al. Chronic spinal pain and physical-mental comorbidity in the United States: results from the national comorbidity survey replication. Pain 2005;115:331-9.

Von Korff M, Simon GE. The relationship between pain and depression. Br J Psychiatry 1996;168:101-8.

Wittchen HU. Reliability and validity studies of the WHO Composite International Diagnostic Interview (CIDI). A critical review. J Psychiatr Res 1994;28:57-84.

Wolter KM. Introduction to Variance Estimation. New York, NY: Springer-Verlag; 1985.

Yap AUJ, Chua EK, et al. Multiple pains and psychosocial functioning/psychologic distress in TMD patients. Int $\mathrm{J}$ Prosthodont 2002;15:461-6. 